\title{
Factors Affecting the Practices of Cervical Cancer Screening among Female Nurses at Public Health Institutions in Mekelle Town, Northern Ethiopia, 2014: A Cross-Sectional Study
}

\author{
Mihret Gebreegziabher, ${ }^{1}$ Nigus Gebremedhin Asefa, ${ }^{1}$ and Semarya Berhe ${ }^{2}$ \\ ${ }^{1}$ Dr. Tewelde Legesse Health Science College, Godena Musse, P.O. Box 306, Mekelle, Ethiopia \\ ${ }^{2}$ Department of Nursing, Mekelle University, Ayder Kifle Ketema, P.O. Box 1871, Mekelle, Ethiopia \\ Correspondence should be addressed to Mihret Gebreegziabher; mihretgher@gmail.com
}

Received 30 November 2015; Revised 24 January 2016; Accepted 3 February 2016

Academic Editor: Hugo Arias-Pulido

Copyright (C) 2016 Mihret Gebreegziabher et al. This is an open access article distributed under the Creative Commons Attribution License, which permits unrestricted use, distribution, and reproduction in any medium, provided the original work is properly cited.

\begin{abstract}
Objective. In Ethiopia, the age-adjusted incidence rate of cervical cancer is high, 35.9 per 100,000 women. Despite this fact, cervical cancer screening coverage in Ethiopia is very low. The objective of this study is to assess the magnitude and factors affecting the practices of cervical cancer screening among female nurse in Mekelle Town, Tigray, Northern Ethiopia, 2014. Methods. This study used a cross-sectional design. Bivariate and multivariate logistic regression was used to evaluate factors associated with cervical cancer screening practice. Results. A total of 225 female nurses participated in the study. The magnitude of cervical cancer screening practice among these nurses was 10.7\%, within the past five years of the survey. Attitude and work place of the respondents were significantly associated with a history of cervical cancer screening practices with an adjusted odds ratio (AOR) of 3.023, 95\% CI (1.134-8.059), and 3.424, 95\% CI (1.080-10.853), respectively. Conclusion. The study showed that the magnitude of the cervical screening practice is very low among nurse health professionals. Negative attitude and workplace were identified to be the predictors of decision for cervical cancer test.
\end{abstract}

\section{Introduction}

Carcinoma of the cervix (cervical cancer) is a malignant neoplasm of the cervical area [1]. Vaginal bleeding, contact bleeding, or (rarely) a vaginal mass may indicate the presence of malignancy and symptoms may appear after the cancer is in its advanced stages. Cervical cancer is preventable and, in most cases, curable, if identified in its early stages [1]. Breast and cervical cancer are the most frequently occurring types of reproductive cancers in women worldwide [2]. Cervical cancer is caused by persistent infection with certain types of Human Papilloma Virus (HPV) and it is the second most common cancer in women with 529,000 new cases each year worldwide. Eighty percent of the cases occur in low-resource countries like Africa, Latin America, and Southeast Asia [3].

Cervical cancer screening is looking for precursors, cervical intraepithelial neoplasia, before a person has any symptom and if abnormal tissues or cancer is found early, it may be easier to treat or cure. To prevent this disease, cervical cancer screening programs are introduced worldwide and the introduction of Papanicolaou (Pap) test led to significant reduction in mortality and morbidity in developed countries [4].

In 1945, American Cancer Society endorsed the use of the cervical smear as an effective cancer prevention test for carcinoma of the uterine cervix [5]. The screening techniques often used are Pap smear test, visual inspection of the acetic acid-painted cervix (VIA), and HPV DNA test. Screening programs in Africa are however often rudimentary or nonexistent and the same is true in Ethiopia [6,7]. Marked decreases in cervical cancer incidence and deaths have been achieved by systematic population-based cytology screening programs in developed nations, from as early as the 1960s [8].

Health workers, especially nurses, are often considered as "role models" in health related issues. Nurses play a major role in enlightening the public on the availability and need 
for cervical cancer screening services. They are informed individuals who are expected to have more information and knowledge about several health related issues and also act as role models in uptake of preventive services, but studies have documented otherwise [9].

In Ethiopia, records showed that nearly 22 million Ethiopian women are over the age of 15 , approximately 7,600 are diagnosed with cervical cancer and roughly 6,000 women die of the disease each year [3]. These figures are probably significantly lower than the actual number of cases and it is projected that the number of new cases will almost double by 2025 [3]. Cervical cancer is fatal if diagnosed in advanced stages. It is treatable in early stages. But, even when the disease is not fatal, the consequences are severe and often lead to physical, psychological, and sexual problems [10].

In developed countries, the proportions of women who are screened by Pap test vary from 68 to 84\% [11]. However, in developing countries, screening coverage is still low, ranging from $2.0 \%$ to $20.2 \%$ in urban areas and from $0.4 \%$ to $14.0 \%$ in rural areas [12]. Different studies showed that very few women in sub-Saharan Africa and other developing countries are ever screened for cervical cancer and low levels of awareness and poor knowledge of cervical cancer coupled with unavailability and inaccessibility of cervical cancer screening services are responsible for the very small number of women being screened [10]. Previous research findings indicated that the magnitude of cervical cancer screening in Ethiopia is very low, which is $0.6 \%$ [7].

\section{Methods}

The study was conducted in public health institutions, which includes health centers and all levels of hospitals in Mekelle Town, Northern Ethiopia. This study used a cross-sectional study design and sample size was determined using the formula for a single population proportion, taking a prevalence estimate of $34.6 \%$ from a previous research conducted in Nigeria [4]. Assuming 95\% confidence interval and margin error of $5 \%(d=0.05)$, the total sample size was calculated as 242 , including $10 \%$ nonresponse rate.

Data were collected using a semistructured questionnaire, which contains both open-ended and closed-ended questions. It was piloted on $5 \%(n=13)$ female nurses to check the consistency and understandability of the questions and slight modification was made based on frequent data quality checks. For example, when investigators realized that many female nurses who work in the health centers have lack of knowledge on the site of the screening service, "I do not know the place of the service" was added as a response to the question "why do not you get a screening for cervical cancer?"

The dependent variable in this study was self-reported history of ever being screened for cervical cancer within the past five years. The independent variables were sociodemographic factors (age, ethnicity, marital status, parity, and level of education), knowledge, attitude, work place, service year, cost, access, and distance of the screening service.

The data were entered and analyzed using SPSS version 20. Bivariate and multivariate logistic regression analysis was run after checking for multicollinearity test between the
TABLE 1: Distribution of female nurses by sociodemographic characteristics in Mekelle City, Tigray, Ethiopia, June 2014.

\begin{tabular}{|c|c|c|}
\hline Characteristic & Frequency $(f)$ & Percent \\
\hline \multicolumn{3}{|l|}{ Age (years) } \\
\hline $20-29$ & 143 & 63.6 \\
\hline $30-39$ & 52 & 23.1 \\
\hline $40-49$ & 26 & 11.6 \\
\hline$\geq 50$ & 4 & 1.8 \\
\hline \multicolumn{3}{|l|}{ Level of education } \\
\hline Diploma & 52 & 23.1 \\
\hline BSC nurses & 162 & 72.0 \\
\hline Postgraduate & 11 & 4.9 \\
\hline \multicolumn{3}{|l|}{ Work experience } \\
\hline $1-2$ years & 30 & 13.3 \\
\hline $3-4$ years & 50 & 22.2 \\
\hline $5-6$ years & 71 & 31.6 \\
\hline$>6$ years & 74 & 32.9 \\
\hline \multicolumn{3}{|l|}{ Workplace (ward, unit) } \\
\hline Outpatient & 55 & 24.4 \\
\hline Surgical ward & 22 & 9.8 \\
\hline Medical ward & 34 & 15.1 \\
\hline Pediatric ward & 31 & 13.8 \\
\hline Gynecology ward & 23 & 10.2 \\
\hline Labor ward & 22 & 9.8 \\
\hline Psychiatric ward & 3 & 1.3 \\
\hline Dermatology & 3 & 1.3 \\
\hline EPI & 8 & 3.6 \\
\hline ANC & 11 & 4.9 \\
\hline $\mathrm{FP}$ & 13 & 5.8 \\
\hline \multicolumn{3}{|l|}{ Marital status } \\
\hline Single & 69 & 30.7 \\
\hline Married & 141 & 62.7 \\
\hline Divorced & 9 & 4 \\
\hline Widowed & 6 & 2.7 \\
\hline \multicolumn{3}{|l|}{ Parity } \\
\hline 1-2 children & 101 & 44.9 \\
\hline 3-4 children & 30 & 13.3 \\
\hline$\geq 5$ children & 2 & 0.9 \\
\hline Null para & 92 & 40.9 \\
\hline \multicolumn{3}{|l|}{ Religion } \\
\hline Orthodox & 221 & 98.2 \\
\hline Others* & 4 & 1.8 \\
\hline \multicolumn{3}{|l|}{ Ethnicity } \\
\hline Tigray & 218 & 96.9 \\
\hline Amhara & 7 & 3.1 \\
\hline
\end{tabular}

* Others indicate Protestant, Muslim, and Catholic.

independent variables. Using multivariate logistic regression analysis, 95\% CI and adjusted odds ratios (AORs), where confounding variables are controlled, were computed in order to identify any statistically significant associations between independent factors and history of cervical cancer test. The level of statistical significance was set at $P<0.05$.

2.1. Knowledge and Attitude Measurement. The understanding of the respondents (knowledge) about carcinoma of 
TABLE 2: Distribution of responses of female nurses on knowledge questions about cervical cancer at Public Health Institutions in Mekelle City, Tigray, Ethiopia, June 2014.

\begin{tabular}{|c|c|c|}
\hline Responses & Frequency $(f)$ & Percent \\
\hline \multicolumn{3}{|l|}{ Risk factors } \\
\hline Multiple sexual partners & 60 & 26.6 \\
\hline Early sexual intercourse & 24 & 10.7 \\
\hline HPV infection & 80 & 35.6 \\
\hline Cigarette smoking & 37 & 16.4 \\
\hline Do not know & 24 & 10.7 \\
\hline \multicolumn{3}{|l|}{ Vulnerability to CCA } \\
\hline Women $>50$ years of age & 86 & 38.1 \\
\hline Reproductive age & 44 & 19.6 \\
\hline Both & 80 & 35.6 \\
\hline Do not know & 15 & 6.7 \\
\hline \multicolumn{3}{|l|}{ Sign and symptoms } \\
\hline Vaginal bleeding & 103 & 45.8 \\
\hline Foul smelling vaginal discharge & 71 & 31.6 \\
\hline Contact bleeding & 42 & 18.6 \\
\hline Do not know & 9 & 4 \\
\hline \multicolumn{3}{|l|}{ Prevention } \\
\hline Avoid multiple sexual partners & 33 & 14.7 \\
\hline Avoiding early sexual intercourse & 27 & 12 \\
\hline Screening and treatment & 59 & 26.2 \\
\hline Avoid/quit cigarette smoking & 37 & 16.4 \\
\hline All of the above & 54 & 24 \\
\hline Do not know & 15 & 6.7 \\
\hline \multicolumn{3}{|l|}{ What are the ways of screening } \\
\hline Pap smear & 70 & 31.1 \\
\hline VIA & 53 & 23.6 \\
\hline Both & 48 & 21.3 \\
\hline Do not know & 53 & 23.6 \\
\hline There is no way of screening & 1 & 0.4 \\
\hline
\end{tabular}

the cervix with respect to the questionnaire on symptoms, risk factors, screening, prevention, and treatment methods was measured using Nahida's KAP (knowledge, attitude, and practice) study, as follows:

(i) 80-100\%: good knowledge;

(ii) 60-79\%: moderate knowledge;

(iii) $<60 \%$ : poor knowledge.

The belief and feeling of the respondents (attitude) about cervical cancer and its screening practice, prevention, cost, severity, susceptibility, and treatment were measured using Likert scale system, which ranges from score 5 (strongly agree) to score 1 (strongly disagree). The responses were summed up and a total score was obtained for each respondent. The mean score was calculated and those who scored equal to or greater than the mean were categorized as having a positive attitude and those who scored below the mean were categorized as having a negative attitude towards cervical cancer screening.

Ethical clearance was obtained from the Institutional Review Board of Mekelle University, College of Health Sciences. This study was approved by the Institutional Review

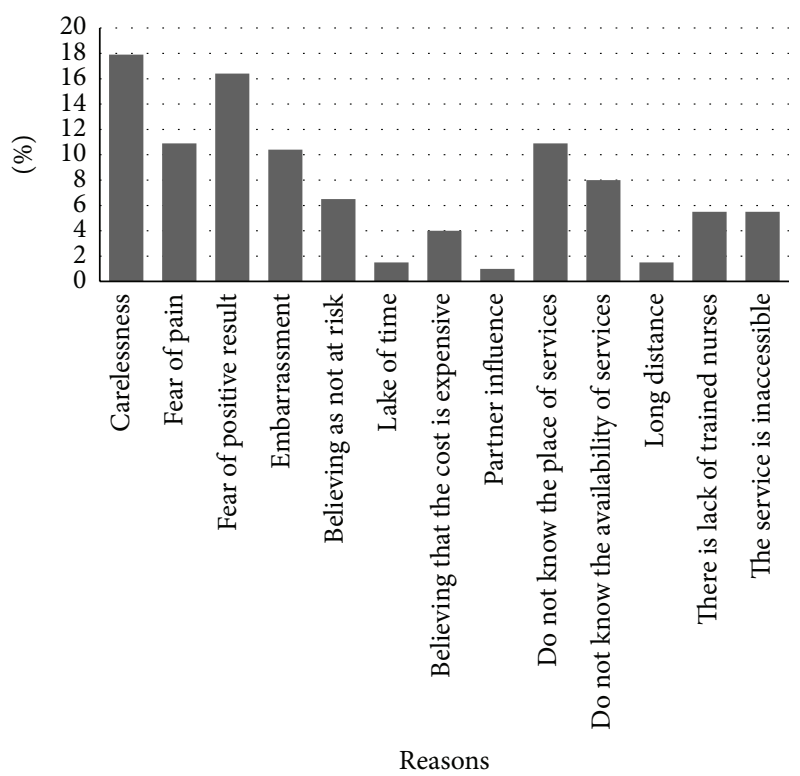

FIGURE 1: Reasons of not being screened for cervical cancer among female nurses at Public Health Institutions in Mekelle City, Tigray, Ethiopia, June 2014.

Board of Mekelle University, College of Health Sciences. Written consent was obtained from all participants and they were informed that participation is voluntary and they can withdraw any time during conducting the study.

\section{Results}

3.1. Sociodemographic Characteristics. The response rate of female nurses in public health institutions in this study was $93 \%$. The data showed that the median age of respondents was 28 years old, with the majority (63.6\%) of respondents in the range of 20-29 years. As seen in Table 1, 72\% of the nurses have a B.S. nurse qualification and $32.9 \%$ of them had work experience of $>6$ years. More than half $(62.7 \%)$ of the study participants were married, and $44.9 \%$ of them had $1-2$ children. The majority (98.2\%) of the nurses were orthodox Christians.

3.2. Knowledge and Attitude of Cervical Cancer. Out of 225 respondents, $80(35.6 \%)$ reported that only HPV was an important predisposing factor for cervical cancer. More than one-third (38.1\%) and $26.6 \%$ of the respondents knew that age and multiple sexual partner as a predisposing factor, respectively. With regard to signs and symptoms of cervical cancer, more than one-third (45.8\%) of the study participants mentioned vaginal bleeding as one of the signs of cervical cancer (Table 2).

As shown in Table 2, from a total of 225 female nurses, $171(76.4 \%)$ know at least one preventive measure of cervical cancer. On the other hand, only $43.1 \%$ of the study participants knew that the preventive measure for cervical cancer is avoidance of predisposing factors. From a total of 225 respondents, 144 (63.1\%) have positive attitudes towards cervical cancer screening, based on Likert scale system (Table 3). 
TABle 3: Responses of female nurses on attitude questions at Public Health Institutions in Mekelle Town, Tigray, Ethiopia, June 2014.

\begin{tabular}{|c|c|c|c|c|c|}
\hline \multirow[b]{2}{*}{ Questions } & \multicolumn{5}{|c|}{ Responses } \\
\hline & Strongly agree (5) & Agree (4) & $\begin{array}{c}\text { Neither agree } \\
\text { nor disagree (3) }\end{array}$ & Disagree (2) & Strongly disagree (1) \\
\hline \multicolumn{6}{|c|}{$\begin{array}{l}\text { Carcinoma of the cervix is highly prevalent in our } \\
\text { country }\end{array}$} \\
\hline Frequency & 47 & 87 & 70 & 19.0 & 2.0 \\
\hline Percent & 20.9 & 38.7 & 31.1 & 8.4 & 0.9 \\
\hline \multicolumn{6}{|c|}{ Screening for cervical cancers is expensive } \\
\hline Frequency & 49 & 73 & 42 & 43 & 18.0 \\
\hline Percent & 21.8 & 32.4 & 18.7 & 19.1 & 8.0 \\
\hline \multicolumn{6}{|c|}{$\begin{array}{l}\text { Screening helps in the prevention of carcinoma of } \\
\text { the cervix }\end{array}$} \\
\hline Frequency & 110 & 76 & 26 & 11 & 2.0 \\
\hline Percent & 48.9 & 33.8 & 11.6 & 4.9 & 0.9 \\
\hline \multicolumn{6}{|c|}{ Screening causes no harm to the client } \\
\hline Frequency & 18 & 20 & 33 & 57 & 97 \\
\hline Percent & 8.0 & 8.9 & 14.7 & 25.3 & 43.1 \\
\hline \multicolumn{6}{|c|}{$\begin{array}{l}\text { Any adult woman including you can acquire cervical } \\
\text { carcinoma }\end{array}$} \\
\hline Frequency & 95 & 81 & 30 & 10 & 9.0 \\
\hline Percent & 42.2 & 36.0 & 13.3 & 4.4 & 4.0 \\
\hline \multicolumn{6}{|c|}{$\begin{array}{l}\text { If screening is free and causes no harm, you will } \\
\text { screen for cervical cancer }\end{array}$} \\
\hline Frequency & 97 & 57 & 33 & 20 & 18 \\
\hline Percent & 43.1 & 25.3 & 14.7 & 8.9 & 8.0 \\
\hline \multicolumn{6}{|c|}{$\begin{array}{l}\text { Pap test can find cervical changes before they } \\
\text { become cancer }\end{array}$} \\
\hline Frequency & 96 & 84 & 31 & 9 & 5.0 \\
\hline Percent & 42.7 & 37.3 & 13.8 & 4.0 & 2.2 \\
\hline \multicolumn{6}{|c|}{ It is embarrassing to go through screening procedure } \\
\hline Frequency & 104 & 92 & 10 & 14 & 5.0 \\
\hline Percent & 46.2 & 40.9 & 4.4 & 6.2 & 2.2 \\
\hline \multicolumn{6}{|c|}{$\begin{array}{l}\text { If you want to get a screening, will you allow male } \\
\text { doctors to examine your cervix }\end{array}$} \\
\hline Frequency & 121 & 74 & 10 & 13 & 7.0 \\
\hline Percent & 53.8 & 32.9 & 4.4 & 5.8 & 3.1 \\
\hline \multicolumn{6}{|c|}{$\begin{array}{l}\text { If you develop cervical cancer, you will consult a } \\
\text { doctor without being scared }\end{array}$} \\
\hline Frequency & 141 & 68 & 7 & 4 & 5.0 \\
\hline Percent & 62.7 & 30.2 & 3.1 & 1.8 & 2.2 \\
\hline
\end{tabular}

3.3. Magnitude of Cervical Cancer Screening Practice. Among the 225 respondents, only $24(10.7 \%)$ nurses reported that they have ever been tested for cervical cancer in the past five years (2009-2014). The most common reasons for not being screened for cervical cancer were carelessness (17.9\%), fear of positive result (16.4\%), and fear of pain (10.9\%), among a list of different reasons (Figure 1).

3.4. Factors Associated with a History of Self-Reported Cervical Cancer Screening Practice. Logistic regression analysis showed that attitude (AOR $=3.023,95 \% \mathrm{CI}: 1.134,8.059)$ and work place $(\mathrm{AOR}=3.424,95 \% \mathrm{CI}: 1.080-10.853)$ were found to be significantly associated with the practice of cervical cancer screening (Table 4). The odds of getting screened for cervical cancer in female nurses who work at outpatient department are 3 times more as compared to female nurses who work in other wards. Similarly, the odds of getting screened for cervical cancer in nurses having a positive attitude are 3.4 times as compared to female nurses who have negative attitudes.

\section{Discussion}

In this study, the practice of cervical cancer screening was $10.7 \%$, which is almost similar to studies conducted in Nigeria (10\%), India (8\%), and Ghana (11.6\%) $[4,13,14]$. However, this is quite different as compared to studies from Sri Lanka (17.2\%) [15], Brazil (94.7\%) [16], and Japan (24\%) [17]. This 
TABLE 4: Factors associated with the practices of cervical cancer screening among female nurses at Public Health Institutions in Mekelle City, Tigray, June 2014.

\begin{tabular}{|c|c|c|c|c|c|}
\hline \multirow[b]{2}{*}{ Characteristics } & \multicolumn{2}{|c|}{ Cervical cancer screening } & \multirow[b]{2}{*}{ COR $(95 \% \mathrm{CI})$} & \multirow[b]{2}{*}{ AOR (95\% CI) } & \multirow[b]{2}{*}{$P$ value } \\
\hline & $\begin{array}{c}\text { Screened } \\
\text { Yes }(\%)\end{array}$ & $\begin{array}{c}\text { Not screened } \\
\text { No }(\%)\end{array}$ & & & \\
\hline \multicolumn{6}{|l|}{ Attitude } \\
\hline Negative & $4(4.8)$ & $79(95.2)$ & 1.0 & 1.0 & \\
\hline Positive & $20(14.1)$ & $122(85.9)$ & $3.24(1.067-9.826)$ & $3.42(1.080-10.853)$ & 0.017 \\
\hline \multicolumn{6}{|l|}{ Work place } \\
\hline Other wards & $8(5.9)$ & $127(94.1)$ & 1.0 & 1.0 & \\
\hline OPD ward & $16(17.8)$ & $74(82.2)$ & $3.43(1.401-8.407)$ & $3.02(1.134-8.059)$ & 0.008 \\
\hline \multicolumn{6}{|l|}{ Marital status } \\
\hline Married & $19(13.5)$ & $122(86.5)$ & 1.0 & 1.0 & \\
\hline Single & $4(5.8)$ & $65(94.2)$ & $.39(.129-1.210)$ & $.64(.189-2.201)$ & 0.214 \\
\hline Separated & $1(6.7)$ & $14(93.3)$ & $.45(.057-3.692)$ & $.36(.042-3.179)$ & 0.666 \\
\hline \multicolumn{6}{|l|}{ Level of education } \\
\hline Diploma & $7(13.5)$ & $45(86.5)$ & 1.0 & & \\
\hline 1st degree and above & $17(9.8)$ & $156(90.2)$ & $.454(.186-1.107)$ & & \\
\hline \multicolumn{6}{|c|}{ Knowledge of cervical cancer } \\
\hline Poor knowledge & $2(5.7)$ & $33(94.3)$ & 1.0 & 1.0 & \\
\hline Moderate knowledge & $14(12.6)$ & $97(87.4)$ & $2.381(.514-11.035)$ & $2.46(.486-12.442)$ & 0.427 \\
\hline Good knowledge & $8(10.1)$ & $71(89.9)$ & $1.859(.374-9.241)$ & $2.4(.432-13.294)$ & 0.474 \\
\hline \multicolumn{6}{|c|}{ Knowledge of cervical cancer prevention } \\
\hline Poor knowledge & $0(0)$ & $152(100)$ & 1.0 & & \\
\hline Moderate knowledge & $17(27.4)$ & $45(72.6)$ & $.913(.109-7.637)$ & & \\
\hline Good knowledge & $7(63.6)$ & $4(36.4)$ & $1.353(.542-3375)$ & & \\
\hline \multicolumn{6}{|l|}{ Age in years } \\
\hline$<30$ years & $10(7)$ & $133(93)$ & 1.0 & 1.0 & \\
\hline$\geq 30$ years & $14(17.3)$ & $67(82.7)$ & $2.738(1.156-6.487)$ & $2.51(.738-8.505)$ & 0.207 \\
\hline \multicolumn{6}{|l|}{ Parity } \\
\hline Nullipara & $8(8.7)$ & $84(91.3)$ & 1.0 & 1.0 & \\
\hline Multipara & $16(12)$ & $117(88)$ & $1.436(.587-3.510)$ & $.75(.231-2.404)$ & 0.177 \\
\hline \multicolumn{6}{|l|}{ Ethnicity } \\
\hline Amara & $0(0)$ & $7(100)$ & 1.0 & & \\
\hline Tigray & $24(11)$ & $194(89)$ & $.708(.082-6.141)$ & & \\
\hline \multicolumn{6}{|l|}{ Service year } \\
\hline $1-3$ years & $2(2.5)$ & $78(97.5)$ & 1.0 & 1 & \\
\hline $4-6$ years & $10(14.1)$ & $61(85.9)$ & $3.864(1.186-12.596)$ & $2.99(.771-11.671)$ & 0.286 \\
\hline$>6$ years & $12(16.2)$ & $62(83.8)$ & $2.303(.663-7.996)$ & $1.166(.252-5.399)$ & 0.381 \\
\hline
\end{tabular}

could be due to the difference in strategies to create a supportive environment and sustainable and cost-effective national policy for comprehensive screening and prevention of cervical cancer.

This study revealed that attitude (AOR $=3.023,95 \% \mathrm{CI}$ : $1.134-8.059)$ and work place (AOR $=3.424$, 95\% CI: $1.080-$ 10.853 ) were found to be significant factors for cervical cancer screening practice. However, attitude and work place of the respondents were not significantly associated with the practice of cervical cancer screening in studies done in Nigeria [4], Japan [18], Brazil [16], Ghana [14], and Japan [17]. This might be due to the fact that cervical cancer screening centers in Ethiopia are very few and are available only in secondary and tertiary hospitals, where most of these services are in outpatient departments [19]. During the data collection, Pap smear test was exclusively performed for all women only in one tertiary hospital (Ayder referral hospital) and one higher health center (Family Guidance Ethiopia, Mekelle Branch). In addition, cervical cancer screening service was available for women with HIV/AIDS in three additional hospitals in the region.

As evidenced by different literatures, including ours, high level of awareness and knowledge of cervical cancer demonstrated by health professionals did not translate to proper utilization of the screening services $[4,18,20]$. This study has demonstrated that women negative attitudes could deter them from up taking cervical cancer screening [21]. This negative attitude could be due to the lack of trust and confidence, where these clients may partially know the service providers. This partial acquaintance can be a source of shy, fright, and anxiety to use the service. However, it should be noted that a combination of different factors 
plays a significant role in women, preventing for cervical cancer screening [21]. On the other hand, studies in highresource settings have found that providing self-sampling kits to women who do not attend regular cytological screening increase their participation [22].

It has been shown that health care provider recommendations are strong predictors of cervical cancer screening for the general population $[20,23]$. These health professionals, who had not tested for themselves, may not initiate and recommend others for screening. The main factor reported for not getting screened was carelessness. The overall poor attitude and carelessness of these female nurses may greatly hamper the screening program. A meta-analysis research conducted by Julinawati et al. showed that women developed positive attitude towards cervical cancer screening only after experiencing significant clinical symptoms, including yellowish discharge or bleeding from the vagina [21]. The result of this study can be considered as an indication of the magnitude of the cervical cancer screening practice in the general population.

\section{Conclusion and Recommendation}

Even though health professionals are expected to be role models in all aspects of health service utilization, the study showed that the magnitude of cervical screening practice is very low among nurse health professionals. Attitude and assignment of work place in the public health institutions were found to be the predictors of cervical cancer test. Let alone the general population, the current screening program is not effective even in reaching female health professionals. Integration of cervical cancer screening into routine reproductive health services should be considered. Efforts should be put in place to influence the attitude and perception of women through public health education. There is a need for sensitization of nurses and other health professionals about cervical cancer and the importance of screening. In addition, appropriate environment should be designed for cervical cancer test.

\section{Conflict of Interests}

The authors declare that there is no conflict of interests regarding the publication of this paper.

\section{Acknowledgments}

The authors would like to forward their gratitude to Department of Nurse, Mekelle University. Their special thanks also go to the administrators of each public health institution. The technical assistant by Haftamu Ebuy was so helpful. They would like also to thank study participants, data collectors, and supervisors for their cooperation during the data collection.

\section{References}

[1] F. Getahun, F. Mazengia, M. Abuhay, and Z. Birhanu, "Comprehensive knowledge about cervical cancer is low among women in Northwest Ethiopia," BMC Cancer, vol. 13, article 2, 2013.
[2] A. M. Amosu, A. M. Degun, A. O. Babalola, and M. A. Thomas, "Level of specific knowledge, awareness, perception, and screening behavior regarding carcinoma of the cervix among rural women in Iwo local government area, Osun State, Nigeria," Annals of Biological Research, vol. 2, no. 2, pp. 206-221, 2011.

[3] Pathfider International, Combating Cervical Cancer in Ethiopia, Addis Tesfa, Pathfider International, Addis Ababa, Ethiopia, 2010, http://www.pathfinder.org/publications-tools/pdfs/Combating-Cervical-Cancer-in-Ethiopia.pdf.

[4] M. O. Oche, A. U. Kaoje, G. Gana, and J. T. Ango, "Cancer of the cervix and cervical screening Current knowledge, attitude and practices of female healthworkers in Sokoto, Nigeria," International Journal of Medicine and Medical Sciences, vol. 5, no. 4, pp. 184-190, 2013.

[5] A. Ombech Elizabeth, W. T. Muigai Anne, and W. Peter, "Awareness of cervical cancer risk factors and practice of Pap smear testing among female primary school teachers in Kasarani division, Nairobi Kenya," African Journal of Health Sciences, vol. 21, no. 2, pp. 121-132, 2012.

[6] O. Awodele, A. A. A. Adeyomoye, D. F. Awodele, V. Kwashi, I. O. Awodele, and D. C. Dolapo, "A study on cervical cancer screening amongst nurses in Lagos University Teaching Hospital, Lagos, Nigeria," Journal of Cancer Education, vol. 26, no. 3, pp. 497-504, 2011.

[7] World Health Organization, Institut Català d'Oncologia: Human Papillomavirus and Related Cancers in Ethiopia, Fact Sheet 2013, 2014, http://www.hpvcentre.net/statistics/reports/ ETH.pdf.

[8] D. M. Parkin, S. L. Whelan, J. Ferlay et al., Cancer Incidence in Five Continents, Volume VIII, IARC Scientific Publications No 155, IARC Press, Lyon, France, 2002.

[9] O. S. Arulogun and O. O. Maxwell, "Perception and utilization of cervical cancer screening services among female nurses in University College Hospital, Ibadan, Nigeria," Pan African Medical Journal, vol. 11, article 69, 2012.

[10] P. N. Abotchie and N. K. Shokar, "Cervical cancer screening among college students in Ghana knowledge and health beliefs," International Journal of Gynecological Cancer, vol. 19, no. 3, pp. 412-416, 2009.

[11] S. Aswathy, M. A. Quereshi, B. Kurian, and K. Leelamoni, "Cervical cancer screening: current knowledge \& practice among women in a rural population of Kerala, India," Indian Journal of Medical Research, vol. 136, no. 2, pp. 205-210, 2012.

[12] J. John, Knowledge, attitude, practice and perceived barriers towards screening for cervical cancers among women aged 18 years and above, in songea urban, Ruvuma Tanzania [Degree of Master of Medicine in Obstetrics and Gynaecology], Muhimbili University of Health and Allied Sciences, 2011.

[13] V. Shah, S. Vyas, A. Singh, and M. Shrivastava, "Awareness and knowledge of cervical cancer and its prevention among the nursing staff of a tertiary health institute in Ahmedabad, Gujarat, India," ecancermedicalscience, vol. 6, article 270, 2012.

[14] R. K. Adageba, K. A. Danso, F. K. Ankobea, D. Z. Kolbilla, and P. Opoku, "Knowledge of cervical cancer and patronage of cervical cancer screening services among female health workers in Kumasi, Ghana," African Journal of Haematology and Oncology, vol. 2, no. 1, pp. 157-161, 2011.

[15] R. I. W. Nilaweera, S. Perera, N. Paranagama, and A. S. Anushyanthan, "Knowledge and practices on breast and cervical cancer screening methods among female health care workers: a Sri Lankan experience," Asian Pacific Journal of Cancer Prevention, vol. 13, no. 4, pp. 1193-1196, 2012. 
[16] A. C. Gonçalves-Silva, C. Murta-Nascimento, and J. Eluf-Neto, "Assessing screening practices among health care workers at a tertiary-care hospital in Sao Paulo, Brazil," Clinics, vol. 65, no. 2, pp. 151-155, 2010.

[17] R. Konno, S. Sagae, H. Yoshikawa et al., "Cervical cancer working group report," Japanese Journal of Clinical Oncology, vol. 40, supplement 1, pp. i44-i50, 2010.

[18] Y. Yoshino, H. Ohta, M. Kawashima et al., "The knowledge of cervical cancer and screening adherence among nurses at a university-affiliated hospital in Japan," The Kitasato Medical Journal, vol. 42, pp. 6-14, 2012.

[19] T. Yifru and G. Asheber, "Knowledge, attitude and practice of screening for carcinoma of the cervix among reproductive health clients at three teaching hospitals, Addis Ababa, Ethiopia," Ethiopian Journal of Reproductive Health, vol. 2, no. 1, pp. 14-22, 2008.

[20] A. Goyal, G. Vaishnav, A. Shrivastava, R. Verma, and A. Modi, "Knowledge, attitude \& practices about cervical cancer and screening among nursing staff in a teaching hospital," International Journal of Medical Science and Public Health, vol. 2, no. 2, pp. 249-253, 2013.

[21] S. Julinawati, D. Cawley, C. Domegan, M. Brenner, and N. J. Rowan, "A review of the perceived barriers within the health belief model on Pap smear screening as a cervical cancer prevention measure," Journal of Asian Scientific Research, vol. 3, no. 6, pp. 677-692, 2013.

[22] M. Gök, D. A. M. Heideman, F. J. Van Kemenade et al., "HPV testing on self collected cervicovaginal lavage specimens as screening method for women who do not attend cervical screening: cohort study," British Medical Journal, vol. 340, Article ID c1040, 2010.

[23] Z. O. Amarin, L. F. Badria, and B. R. Obeidat, "Attitudes and beliefs about cervical smear testing in ever-married Jordanian women," Eastern Mediterranean Health Journal, vol. 14, no. 2, pp. 389-397, 2008. 


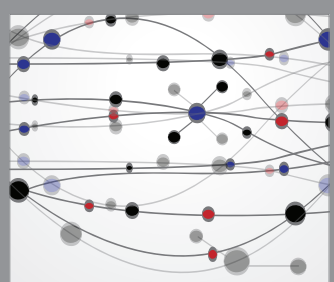

The Scientific World Journal
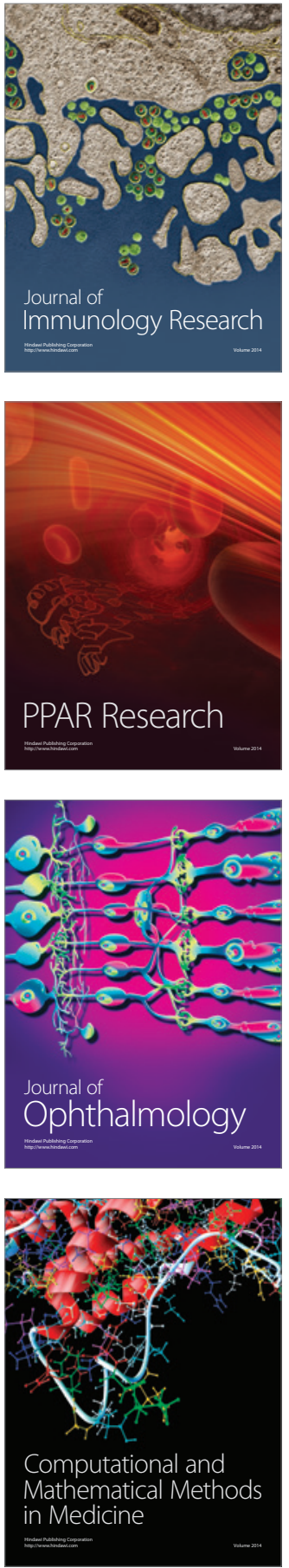

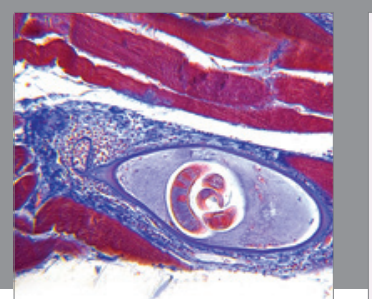

Gastroenterology Research and Practice



\section{Hindawi}

Submit your manuscripts at

http://www.hindawi.com
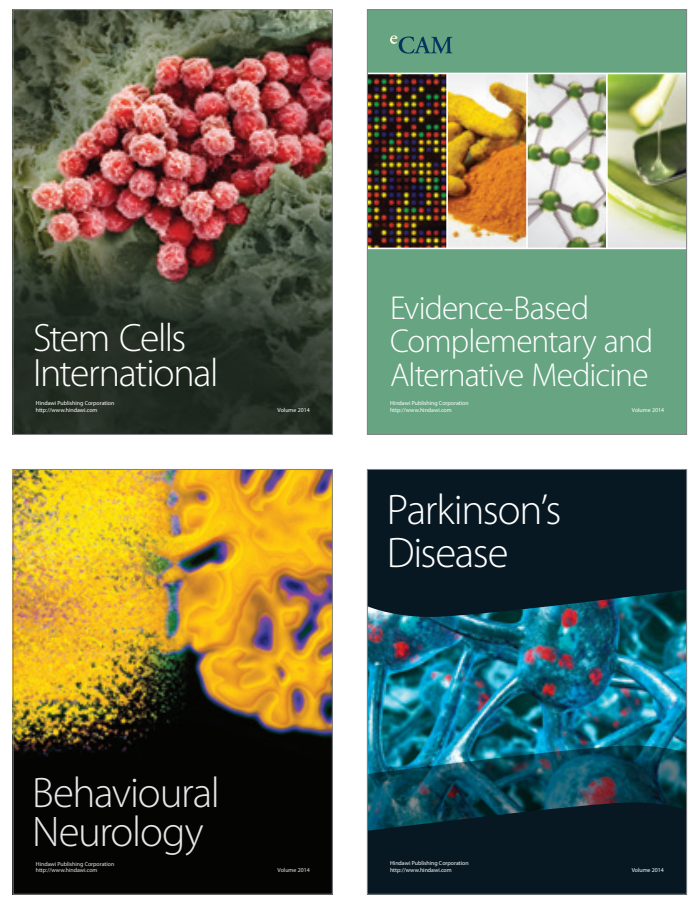
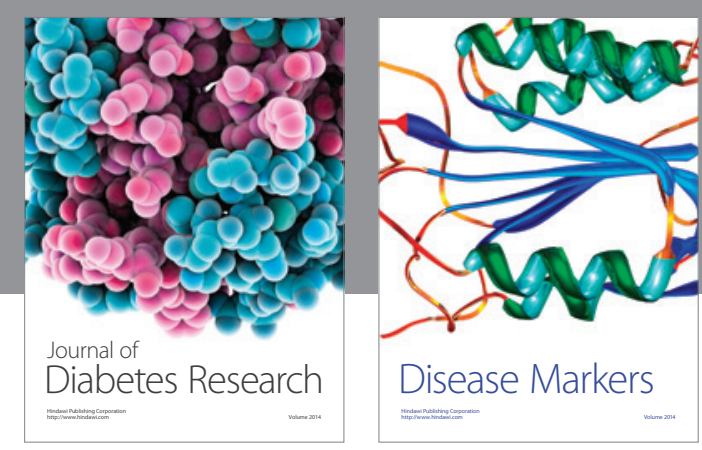

Disease Markers
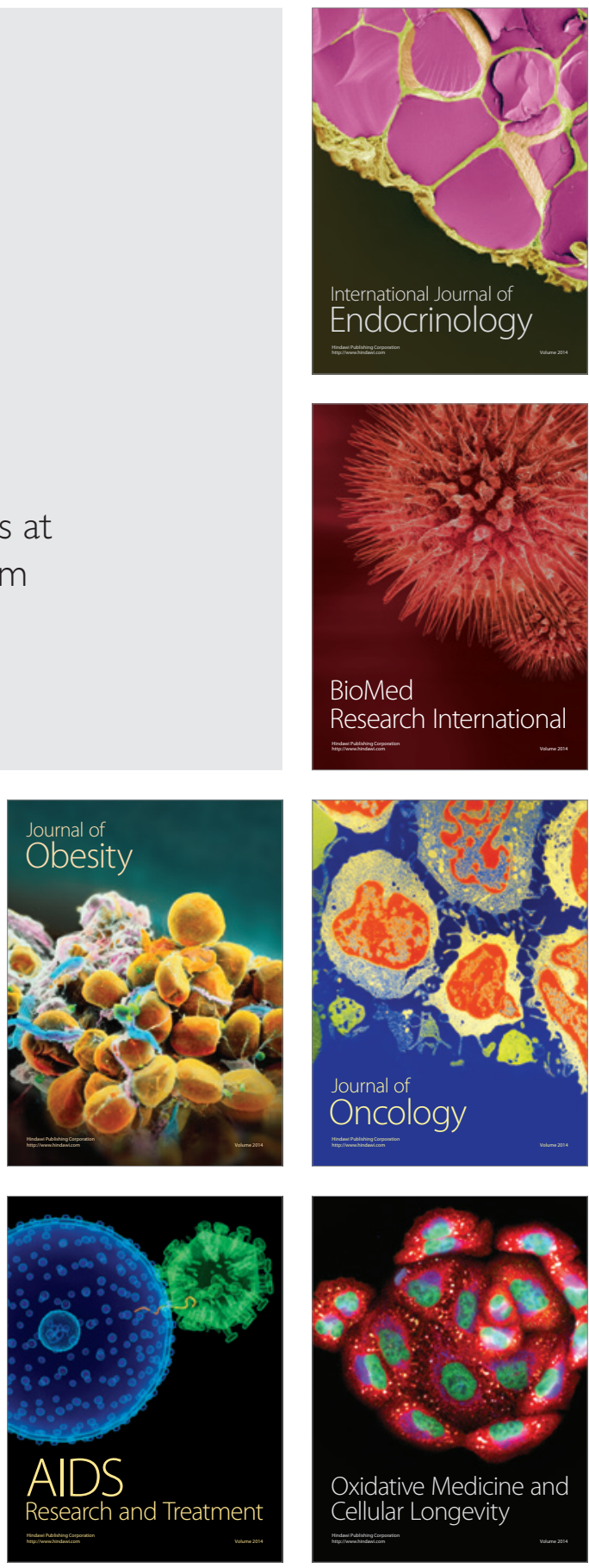